\title{
A Comparative Study on Effect of Caregivers Training on Health Outcomes of HIV Infected Children on Antiretroviral Therapy in Kenya
}

\author{
Argwings Odhiambo Miruka ${ }^{1 *} \quad$ Louisa Ndunyu $^{1} \quad$ Patrick Onyango $^{1}$ \\ Jonah Maswai $^{2} \quad$ Laura Oyiengo $^{3}$ \\ 1. Maseno University, School of Public Health and Community Development P. O Box 333, MASENO. Postal \\ Code 40105 Kenya \\ 2. DOD/ HJF-SRV HIV Program, KEMRI/ Walter Reed Project, P.O. Box 1,357 (20200) Kericho, Kenya. 3. \\ Kenya Ministry of Health, Department of Child health, P.O BOX 447400506 Nairobi, Kenya
}

\begin{abstract}
The purpose of this cohort study was to assess the effect of caregiver training on health outcomes of HIV-infected children aged 1-14 years on antiretroviral therapy in South Rift Valley, Kenya. Three hundred and twenty children of trained caregivers and 778 children of non-trained caregivers were targeted from four hospitals. Population proportionate to size sampling technique was used to calculate number of children enrolled. Children medical chart for trained and non-trained caregivers were stratified as per year of training, 2014, 2015, 2016 and randomly selected numbers matched with corresponding medical record. Data was collected through review of medical records, questionnaires and caregivers interview. There was significant association between caregiver training and adherence (Fisher's Exact Test $\mathrm{X}^{2}=22.740, p=.001$ ). Children of trained caregivers had significant reductions in viral load (Kruskal Wallis $\mathrm{X}^{2}=7.124, p=.028$ ); significant difference in viral loads was also observed between trained and non-trained caregivers (Mann-Whitney $\mathrm{U}=19846, p=.012$ ), significant association in episodes of opportunistic infections before, after and among non-trained caregivers (Fisher's Exact Test $\mathrm{X}^{2}=76.768, p=.001$ ). Nutritional status of children was not associated with caregivers training (Pearson Chi-square $\mathrm{X}^{2}=11.616, p=.072$ ). Most caregivers perceived training to be useful. The study found that, training enables caregivers to improve adherence levels of HIV infected children on antiretroviral therapy. Even though there are HIV information in public domain, the study found, if this information is provided in a structured manner, enables suppression of viral loads of HIV infected children. Training caregivers significantly reduces frequency of opportunistic infections among HIV infected children on antiretroviral therapy. Providing information on nutrition to caregivers does not affect nutritional status of HIV infected children. Training caregivers on HIV information improves health outcomes of HIV infected children thus study provide evidence-based decision making in rolling out caregivers training nationally.
\end{abstract}

Keywords: HIV, Caregivers, Training, Children, Adherence,

DOI: $10.7176 / \mathrm{JHMN} / 76-05$

Publication date:June 30th 2020

\section{Introduction}

Globally, at the end of 2016, nearly 11.5 million individuals including 1.1 million children were living with HIV(UNAIDS, 2017). HIV and AIDS is a leading cause of morbidity and mortality in pediatric populations(Wattradul \& Sriyaporn, 2014). Vast majority of more than $90 \%$ of HIV infected children younger than 15 years of age live in sub-Saharan Africa(Killian \& Levy, 2011). The region also carries the highest global burden of pediatric HIV and AIDS. As of December 2015, 49\% of all HIV infected children were accessing treatment ${ }^{1}$. While this was a significant improvement for children, it still meant that over half of children living with HIV were still in urgent need of ART (UNAIDS, 2017). Regular HIV testing, treatment, monitoring and care for HIV infected children can enable them live long and fulfilling lives. Advances in treatment and prevention of HIV infection have resulted in dramatic improvements in morbidity and mortality of children in developed countries. However, the scale up of diagnosis and provision of care and treatment to these children in developing countries continues to lag behind (UNAIDS, 2017).

Even though UNAIDS established new targets in 2013, concerns still remain that pediatric sub-populations lags behind across the entire cascade right from identification of all HIV infected children, ART adherence and viral suppression in contrast to adults HIV treatment. Africa and especially sub-Saharan region continues to face challenges including ART non-adherence and poor viral suppression. Adherence in SSA children is low at $48.4 \%$ compared to $80.6 \%$ in adults counterparts(NACC, 2016). In Kenya, for example, viral suppression rates among children has remained low at $43.2 \%$ as compared to $75.4 \%$ in adults(Eticha \& Berhane, 2014). There is a dearth of scientific knowledge on effect of caregivers training on pediatric adherence, viral suppression, opportunistic infections and nutritional status among HIV infected children. In addition, even though prevalence of opportunistic infections has declined since the advent of Highly Active Antiretroviral Therapy, the prevalence of opportunistic 
infections in children has remained relatively high in developing countries(B-Lajoie et al., 2016). Pneumonia and other opportunistic infections remain a major cause of death and hospitalization among HIV infected children(Alarcón et al., 2012).

There are also challenges of increased nutritional needs among children living with HIV. These places additional burden that ultimately increase morbidity and mortality risks in HIV infected children. Severe acute malnutrition, moderate acute malnutrition and micronutrient deficiencies are common in HIV infected children, especially in those not on ART and having other co-morbidities(Mwiru et al., 2015). HIV infected children depend on caregivers to adhere to medication, psychosocial support and other basic needs. However most caregivers do not understand HIV treatment plans to enable them to competently discharge this role(Polisset et al., 2009). Tremendous progress has been made in the fight against HIV pandemic. However, not much progress has been achieved in children's treatment compared to adults. Children with HIV face challenges of adherence, viral suppression, opportunistic infections and malnutrition. Most caregivers do not understand treatment plan to care for these children. Although most caregivers in Kenya were trained between 2014 and 2017 on HIV, the effectiveness of caregivers training on treatment outcomes remain unknown. Caregivers training program for HIV infected children was the first of its kind in Kenya. It was undertaken in the South Rift Valley (SRV) part of the country primarily to address the problem of adherence and high pediatric viral load. This novel intervention involving caregivers training was initiated in 2014 in four sites located in Kericho, Bomet, Nandi and Narok counties of SRV supported by MoH collaborating with Walter Reed project (MoH/WRP). There were 68 pediatric HIV clinics in SRV, which were involved in prevention, care, and treatment with over 1800 children on ART with support of MoH/WRP. Caregivers training intervention was meant to improve medical literacy levels of caregivers of HIV infected children enrolled in Comprehensive Care Centers (CCC). About 350 caregivers have been trained since 2014. This study aimed to evaluate the effect of this intervention on health outcomes of HIV infected children on antiretroviral therapy.

\subsection{Methods}

1.1.1 Study design

This retrospective cross-sectional cohort study design involved evaluation of effect of training 12 months after each training session. This evaluation study was conducted in 2018 after all the groups had been trained. The study sites were four-referral hospitals, where the intervention took place. Kericho County referral hospital serves a population of 758,339 persons(KDHS, 2014). The CCC at the hospital had enrolled about 700 HIV infected children and about 120 caregivers trained as at the end of 2017. The Nandi Hills County hospital serves a population of approximately $360,00{ }^{11}$. During the same year, the hospital had enrolled over 3,000 patients living with HIV including over 200 children, and had trained 80 caregivers. Transmara hospital CCC had enrolled over 2,800 patients including about 300 children with 80 caregivers had been trained. Longisa County referral hospital serves over 974,315 individuals(KDHS, 2014). The hospital CCC had enrolled over 8,500 patients living with HIV including 600 children and 40 caregivers trained.

1.1.2 Intervention description

The three-day health facility-based intervention had caregivers trained between 2014 and 2017. The selection of caregivers to be trained was based on those caregivers that were deemed to need interventions, that is, those whose children had high viral loads, non-adherent to ARVs, and had frequent episodes of opportunistic infections. The intervention was the first of its kind in Kenya that was undertaken in the South Rift Valley to address the problem of high pediatric viral load and enable long-term support. The training was conducted in a local language that caregivers understood i.e. "Kiswahili". The training program included overview of HIV situation in Kenya, laboratory investigations, clinical follow up, HIV and AIDS information, modes of transmission, child development, adherence, nutrition, opportunistic infections, disclosure of HIV status, roles of caregivers, and capacity on socio-economic knowledge.

1.1.3 Study population and sampling procedure:

The Fischer's formula (1991) was used to calculate the sample size of children. The study sites recruitments were as follows; Kericho 65 (37.2\%), Longisa 22(12.6\%), Nandi 44(25.1\%), Transmara 44(25.1\%). 
Table 1 Sampling Scheme for study and participants

\begin{tabular}{lccccc}
$\begin{array}{l}\text { Study } \\
\text { Hospitals }\end{array}$ & $\begin{array}{c}\text { Total Current } \\
\text { children (Active) }\end{array}$ & $\begin{array}{c}\text { Number of } \\
\text { trained caregivers }\end{array}$ & $\begin{array}{c}\text { Sample size } \\
\text { for non-trained } \\
\text { caregivers }\end{array}$ & $\begin{array}{l}\text { No. of } \\
\text { caregivers } \\
\text { trained }\end{array}$ & $\begin{array}{l}\text { Sample size } \\
\text { for trained } \\
\text { caregivers }\end{array}$ \\
\hline Kericho & 680 & 560 & 190 & 120 & 65 \\
Nandi hills & 108 & 28 & 10 & 80 & 44 \\
Longisa & 139 & 99 & 34 & 40 & 22 \\
Transmara & 151 & 71 & 24 & 80 & 44 \\
TOTAL & 1078 & 778 & 258 & 320 & 175
\end{tabular}

Table 2 above shows socio-demographic characteristics of trained and non-trained caregivers

1. 1. 4 Data collection and analyses

The study compared differences and associations in health outcomes of ART adherence, viral suppression, occurrence of opportunistic infections, and nutrition status among HIV infected children before, after training and between trained and non-trained caregivers. Primary data was collected by use of questionnaires and face-to-face interviews. Questionnaires captured caregiver responses to questions on demographics, ART adherence, viral loads, opportunistic infections, nutrition and knowledge about HIV. Face to face interview with caregivers was performed to collect their knowledge of HIV and AIDs, benefits of training, and their perspectives on key components of caregiver training. The interview schedule comprised of various questions including caregivers recollection of training program, what caregivers found helpful, what they wished was different and their recommendation about the training program. Secondary data was collected by reviewing of medical records of HIV infected children. After consenting, research assistants completed participants information forms, performed baseline data abstraction at the point where each caregiver was trained. The end line data was abstracted from children medical record one year after caregiver training. Descriptive statistics, Fisher's Exact Test, Kruskal Wallis, Mann-Whitney, and Pearson Chi-square statistical tests were performed and data analyzed using SPSS version 23.

\subsection{Results}

1.2. 1 Socio- demographic characteristics of caregivers and children

Table 2: Socio-demographic characteristics of trained and non-trained caregivers $(\mathrm{N}=175)$

\begin{tabular}{llcc}
\hline Socio-demographic characteristics of trained & $21-30$ & $\mathbf{N}$ & $\mathbf{\%}$ \\
\hline Age (years) & $31-40$ & 19 & 10.9 \\
& $41-50$ & 64 & 36.6 \\
& $51-60$ & 67 & 38.3 \\
& Over 60 & 13 & 7.4 \\
\hline Gender & Male & 12 & 6.9 \\
\hline Education level & Female & 26 & 14.9 \\
& Never gone to school & 149 & 85.1 \\
\hline & Primary & 30 & 17.1 \\
& Secondary & 32.6 \\
& Tertiary & 57 & 18.3 \\
& University & 32 & 29.1 \\
Marital status & Single & 51 & 2.9 \\
\hline & Cohabiting & 5 & 18.9 \\
& Married & 33 & 1.7 \\
& Divorced & 3 & 54.9 \\
& Widower & 96 & 6.3 \\
\hline Employment & Separated & 11 & 13.1 \\
& Decline to answer & 23 & 4.0 \\
\hline Religion & Yes & 7 & 1.1 \\
\hline & No & 2 & 29.1 \\
& Christian & 51 & 70.9 \\
\hline
\end{tabular}




\begin{tabular}{llcc}
\hline \multicolumn{3}{l}{ Table 2: Socio-demographic characteristics of trained and non-trained caregivers(N=175) } \\
\hline Socio-demographic characteristics of non-trained caregivers & $\mathbf{N = 2 5 8}$ & $\mathbf{\%}$ & .8 \\
\hline Age of caregivers (years) & $10-20$ & 2 & 15.1 \\
& $21-30$ & 39 & 53.1 \\
& $31-40$ & 137 & 26.0 \\
& $41-50$ & 67 & 2.7 \\
& $51-60$ & 7 & 2.3 \\
\hline Education level & Above 60 & 6 & 7.0 \\
& No Education & 18 & 57.4 \\
& Primary & 148 & 33.3 \\
& Secondary & 86 & 2.3 \\
\hline Type of caregivers & Tertiary & 6 & 9.3 \\
& Aunty/Uncle & 24 & 39.5 \\
& Both Parents & 102 & 3.5 \\
& Grandmother/Father & 9 & 32.2 \\
& Single parent -Father & 83 & 10.9 \\
\hline
\end{tabular}

Table 2 above shows Socio-demographic characteristics of trained and non-trained caregivers

1. 2. 2 Socio-demographic characteristics of children of trained and non-trained caregivers

Among the children of trained caregivers, the mean age of the children was $10.45 \pm 3.54$ years ranging between 2 to 14 years. (Among 175 children, 16(9.1\%) were ranging between 0-5years, 48(27.4\%) ranging between 6-10, and $111(63.4 \%)$ ranging between 11-14years. Children were almost equal in gender with females $89(51 \%)$ and males 86(49\%). Most $174(99.4 \%)$ children lived with their families with 132(75.4\%) living in rural area.

Table 3 Socio-demographic characteristics of children of trained caregiver $(\mathbf{N}=175) \quad \%$

\begin{tabular}{|c|c|c|c|}
\hline \multirow[t]{10}{*}{ Relationship to Caregiver } & Own parent & 118 & 67.4 \\
\hline & Step mother & 3 & 1.7 \\
\hline & Sister & 3 & 1.7 \\
\hline & Brother & 1 & 6 \\
\hline & Uncle & 3 & 1.7 \\
\hline & Aunt & 13 & 7.4 \\
\hline & Grandfather & 7 & 4.0 \\
\hline & Grandmother & 22 & 12.6 \\
\hline & Guardian & 4 & 2.3 \\
\hline & Other & 1 & .6 \\
\hline \multirow[t]{5}{*}{ Education Level } & ECD & 52 & 29.7 \\
\hline & Lower primary (1-3) & 64 & 36.6 \\
\hline & Upper Primary (4-8) & 42 & 24.0 \\
\hline & Secondary (1-4) & 10 & 5.7 \\
\hline & No school & 7 & 4.0 \\
\hline \multirow[t]{7}{*}{ Disclosure of HIV status } & Farther & 47 & 26.9 \\
\hline & Grand parent & 40 & 22.9 \\
\hline & Aunt & 13 & 7.4 \\
\hline & Childs uncle & 29 & 16.6 \\
\hline & Brothers and Sisters & 35 & 20.0 \\
\hline & None & 4 & 2.3 \\
\hline & Others & 7 & 4.0 \\
\hline \multirow[t]{7}{*}{ Type of Caregiver } & Aunty/Uncle/Both & 8 & 4.6 \\
\hline & Parents & 44 & 25.1 \\
\hline & Grandparents & 37 & 21.1 \\
\hline & single parent-mother & 47 & 26.9 \\
\hline & single parent -father & 6 & 3.4 \\
\hline & Sibling/Guardian & 27 & 15.4 \\
\hline & Other & 6 & 3.4 \\
\hline \multirow[t]{3}{*}{ Parental Status } & Total orphan & 23 & 13.1 \\
\hline & Single Orphan & 76 & 43.4 \\
\hline & Both parents alive & 76 & 43.4 \\
\hline
\end{tabular}

Table 3 above shows selected socio-demographic characteristics of children of trained and non-trained caregivers. 
Table 4 Socio-demographic characteristics of children of non-trained caregivers $(\mathrm{N}=\mathbf{2 5 8}) \quad \%$

\begin{tabular}{llcc}
\hline Age of child (years) & $1-5$ & 44 & 17.1 \\
& $6-10$ & 96 & 37.2 \\
& $11-15$ & 118 & 45.7 \\
\hline Gender of child & Male & 126 & 48.8 \\
& Female & 132 & 51.2 \\
\hline Education of child & ECD & 24 & 9.3 \\
& $1-3$ Lower primary & 99 & 38.4 \\
& $4-8$ upper primary & 99 & 38.4 \\
& Secondary & 17 & 6.6 \\
& No school & 19 & 7.4 \\
\hline Where child gets support & Family & 250 & 96.9 \\
& Community & 3 & 1.2 \\
& Organization(OVC) & 1 & .4 \\
& Family and Community & 4 & 1.6 \\
\hline Schooling status & In School & 242 & 93.8 \\
& Not in school & 16 & 6.2 \\
\hline Parental status & Total orphan & 34 & 13.2 \\
& Single orphan & 115 & 44.6 \\
& Both parents alive & 105 & 40.7 \\
& Child headed home & 4 & 1.6
\end{tabular}

Table 5 above shows socio-demographic characteristics of children of non-trained caregivers

1. 2. 3 Effect of caregivers training on ART adherence

Table 4 shows frequencies of adherence levels of children before, after training and of non-trained caregivers. Baseline adherence profiles of the 175 children of trained caregivers were as follows: $129(73.7 \%)$ had good adherence, $13(7.4 \%)$ inadequate adherence, and $33(18.9 \%)$ poor adherence. After training, the number of children with good adherence increased to $140(80 \%)$ good adherence whereas those with inadequate adherence was $16(9.1 \%)$ and those with poor adherence was $19(10.9 \%)$. For children of non-trained caregivers, $164(63.6 \%)$ had good adherence, inadequate $51(19.8 \%)$ and poor $43(16.7 \%)$.

Table 5 Frequency of adherence level of children

\begin{tabular}{lllll} 
& \multicolumn{3}{c}{ Adherence } & \\
\cline { 2 - 4 } & Good & Inadequate & Toor & 175 \\
Before training & 129 & 13 & 33 & 175 \\
After training & 140 & 16 & 19 & 258 \\
Non trained & 164 & 51 & 43 & 608 \\
Total & 433 & 80 & 95 & \\
\hline
\end{tabular}

1. 2. 4 Effect of caregivers training on viral load

Figure 1 shows the median viral load before, after training and among non-trained. There were significant differences in viral loads of children at the three measurement points (Kruskal Wallis $\mathrm{X}^{2}=7.124, p=0.028$ ). Among the trained caregivers, comparisons showed a significant difference in viral loads of children before and after training (Wilcoxon signed Rank Test $\mathrm{Z}=-4.461, p=.000$ ). Additionally, there was a significant difference in viral loads of children of trained and non-trained caregivers (Mann-Whitney $\mathrm{U}=19846, p=.012$ ).

Fisher's Exact Test showed there was significant association in ART adherence levels between training

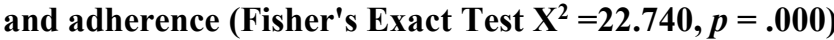




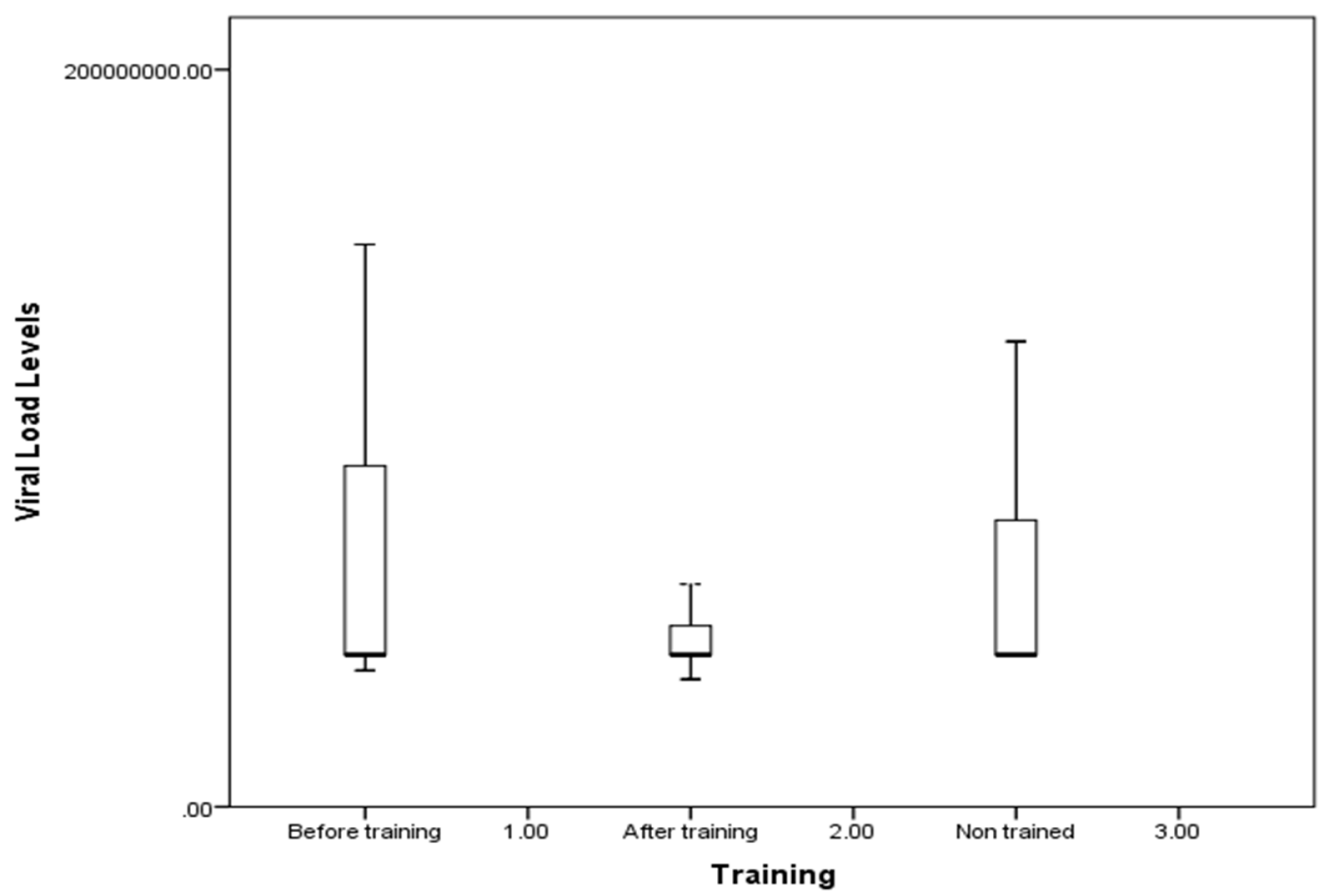

Figure 1. Median viral load of children as a function of caregiver training.

1. 2. 5 Effect of caregivers training on occurrence of opportunistic infections

At baseline there were 62(35.4\%) children with opportunistic infections and 113(64.6\%) without opportunistic infections before training. After training the frequency dropped to 3(2\%) children with opportunistic infections while 172(98\%) experienced no occurrence of opportunistic infections. Among children of non-trained caregivers, 43(16.7\%) had opportunistic infections, while 215(83.3\%) experienced no occurrence of opportunistic infections. Results from ANOVA on effect of caregivers training on opportunistic infections showed, there was a significant effect of caregiver training on occurrence of opportunistic infections among these children $[\mathrm{F}(2,605)=40.246, p$ $=.000]$. There was also significant difference in occurrence of opportunistic infections among children before and after caregivers training (Post Hoc Test, $p=.000$ ). Similarly, there was significant association between occurrence of opportunistic infections in children and caregiver training (before training, after training and non-trained) (Fisher's Exact Test $\mathrm{X}^{2}=77.67, p=.000$ ).

Table 6 Frequency of opportunistic infections among children of trained and non-trained caregivers

\begin{tabular}{|c|c|c|c|}
\hline \multirow[t]{2}{*}{ Caregivers Training } & \multicolumn{2}{|c|}{$\begin{array}{c}\text { Frequency of } \\
\text { Opportunistic infection }\end{array}$} & \multirow[t]{2}{*}{ Total } \\
\hline & Yes & No & \\
\hline Before training & 62 & 113 & 175 \\
\hline After training & 3 & 172 & 175 \\
\hline Non-trained & 43 & 215 & 258 \\
\hline Total & 108 & 500 & 608 \\
\hline
\end{tabular}

Table 6 above shows frequency of opportunistic infections among children of trained and non-trained caregivers 1.2.6 Effect of caregivers training on nutritional status

Table 6 shows nutritional diagnoses among children before training, after training and among children of nontrained caregivers. At baseline, among the 175 trained caregivers, their children $120(68.6 \%)$ had normal nutritional status, $17(9.7 \%)$ had moderate malnutrition, $37(21.1 \%)$ had severe malnutrition, while $1(0.5 \%)$ was overweight. After caregivers training intervention 129(73.7\%) children had normal nutritional status, $19(10.9 \%)$ had moderate malnutrition, 20(11.4\%) had severe malnutrition, while 7(0.04\%) were overweight. Among the 258 non-trained caregivers, their children, $191(74.0 \%)$ had normal nutritional status, $20(7.8 \%)$ had moderate malnutrition, $42(16.3 \%)$ had severe malnutrition, while $5(2.9 \%)$ were overweight 
Table 7 Nutritional diagnosis of children as a function of caregiver training

\begin{tabular}{lccccc}
\hline & \multicolumn{5}{c}{ Nutritional diagnoses } \\
\cline { 2 - 6 } & $\begin{array}{c}-3 \mathrm{SD} / \\
(\text { Normal) } \\
(<-\mathbf{1})\end{array}$ & $\begin{array}{c}\text {-2SD/ moderate } \\
\text { Malnutrition } \\
(<-\mathbf{2} \text { to } \mathbf{- 1})\end{array}$ & $\begin{array}{c}\text { Severe } \\
\text { Malnutrition } \\
\mathbf{( - 3} \text { to } \mathbf{- 2})\end{array}$ & $\begin{array}{c}\text { Overweight } \\
(+\mathbf{2} \text { to }<+\mathbf{3})\end{array}$ & Total \\
\hline Before training & 120 & 17 & 37 & 1 & 175 \\
After Training & 129 & 19 & 20 & 7 & 175 \\
Non trained & 191 & 20 & 42 & 5 & 258 \\
Total & 440 & 56 & 99 & 13 & 608 \\
\hline
\end{tabular}

Table 7 above shows Fisher's Exact Test analysis showed there was no significant association between caregivers training and nutritional status of the children. $\mathrm{X}^{2}=11.350, p=.072$ ).

1. 2. 7 Caregivers Perspectives on HIV and AIDs Training.

Table 8 Caregivers' perspectives on HIV and AIDs training

\begin{tabular}{|c|c|c|}
\hline Caregivers recollection of training program & $(\mathrm{N}=1005)$ & $\%$ \\
\hline HIV/AIDS & 19 & 2.0 \\
\hline Disclosure & 72 & 7.2 \\
\hline Nutrition & 139 & 14.0 \\
\hline ART Adherence & 133 & 13.2 \\
\hline Laboratory testing & 27 & 2.7 \\
\hline Role of caregivers & 30 & 3.0 \\
\hline Opportunistic & 85 & 8.5 \\
\hline Infections & 191 & 19.0 \\
\hline Stigma and discrimination & 17 & 2.0 \\
\hline Psychosocial support & 80 & 8.2 \\
\hline Prevention with positive & 17 & 2.0 \\
\hline Others NHIF & 184 & 18.3 \\
\hline Caregivers Perceived Benefits of Training & $(\mathrm{N}=\mathbf{2 5 0})$ & $\%$ \\
\hline Empowered me with HIV and AIDS knowledge & 47 & 18.8 \\
\hline Keeping me on track with child medication & 54 & 21.6 \\
\hline Keeping on track with child appointments & 20 & 8 \\
\hline Learning more about my child disease & 6 & 2.4 \\
\hline Learnt about CD4 and viral load & 10 & 4 \\
\hline Helped feel less Stigmatized & 24 & 9.6 \\
\hline Learnt about caregivers role on disclosure & 8 & 3.2 \\
\hline Prevention of Opportunistic infections & 8 & 3.2 \\
\hline Learnt about nutrition & 27 & 10.8 \\
\hline Helped care for the child & 37 & 14.8 \\
\hline Family planning & 4 & 1.6 \\
\hline Psychosocial support for the child & 3 & 1.2 \\
\hline What Caregivers Wished was Different about Training & $\mathbf{N}=\mathbf{1 7 5}$ & $\%$ \\
\hline Train all caregivers & 128 & 15.0 \\
\hline Let hospital have frequent trainings of caregivers & 30 & 3.0 \\
\hline Include teaching on love to HIV infected children & 1 & 8.0 \\
\hline Increase training days to one week & 4 & 3.0 \\
\hline Introduce more topics & 3 & 3.2 \\
\hline Reduce training hours & 1 & 29.4 \\
\hline Introduce religious education & 1 & 2.0 \\
\hline End training early & 1 & 2.3 \\
\hline Increase allowance & 1 & 11.1 \\
\hline Nothing to change about training & 4 & 23.0 \\
\hline
\end{tabular}

The above table shows 1473 responses from 175 caregivers interviewed to seek their perspective on various aspects of the training. Caregivers were able to remember topics on nutrition, adherence and other aspects of training program. They perceived that training helped them keep track on children medication and found training to be useful

\subsubsection{DISCUSSION}

This study sought to evaluate effect of caregivers training on health outcomes of HIV infected children aged 1-14 
years on ART in four study sites in South Rift Valley region of Kenya where the intervention took place. This study found training caregivers on HIV and AIDS information improved ART adherence levels of children. This result was consistent with what Biadgilign and colleagues found in their study that showed adherence is driven in part by caregivers knowledge of child's HIV medication regimen(Biadgilign et al., 2011). Parents of adherent children report higher perceptions of their ability to administer prescribed doses(Wattradul \& Sriyaporn, 2014) leading to improvements in ART adherence. Ability, in this case depends on caregivers' cognitive and technical skills to follow a medication scheme including child's ARVs dosage and dosing frequency. Caregivers' ability to follow ARV regimen is of significance in maintaining high adherence levels. Non-trained caregivers in this study had a higher good adherence $63.6 \%$ and $16.7 \%$ poor adherence as compared to findings in West Africa, with $42 \%$ of caregivers declared as having perfect adherence, and $58 \%$ poor adhere to the ART(Okomo et al., 2012). Another study looking at prevalence of adherence in Brazil estimated adherence to ARV treatment in children living in Porto Alegre at 49.5\%(Ricci, Martins, Luz, Rodamilans, \& Brites, 2017). This was lower than non-trained caregiver in this study. This difference may be because HIV and AIDS information is currently available to populations as compared to over 17 years ago when Dulmen and colleagues did the study in 2009(Dulmen et al., 2008). Also trained and non-trained caregivers were in the same community and attended same clinics so fusion of HIV and AIDS information was likely. In addition, there were no socio-demographic differences between intervention and non-intervention group of caregivers. Generally, there is a strong association between caregiver factors and children's adherence to ART (Nyando, 2014)'(Wattradul \& Sriyaporn, 2014)'(Xu, Munir, Kanabkaew, \& Le Coeur, 2017)'(Ricci et al., 2017)'( Sivapalasingam et al., 2014). In this study, a good number of caregivers had good knowledge of their children's medication regimen and could identify the drugs their children were taking after training. It is important to bring out the positive effect of training in that, the caregivers in the intervention group had children who were worse off in health status at baseline but made tremendous improvement after the intervention.

On the question of whether there was effect of caregivers training on viral load, the training contributed to a reduction in viral load levels of children after training. This can be attributed to content of the training package, which provided information on ART adherence, clinic appointments, helping caregivers understand the meaning of viral load, and how ART interferes with HIV replication and reduction of viral load levels in HIV infected children. On the contrary, untrained caregivers were limited to few minutes of unstructured general HIV and AIDS information while waiting on the queue for clinical review, which was insufficient to improve their children's health outcomes. This information is corroborated by a study that looked at treatment outcomes among HIV-1 and HIV-2 infected children initiating ART in a concentrated low prevalence setting in West Africa(Okomo et al., 2012). The study found HIV infected children not on ART do not achieve virologic suppression(Okomo et al., 2012). Another study on caregivers of HIV infected children reported missed doses do not predict virologic response to treatment, but pharmacist medication reconciliation correlated strongly with virologic response(Bhattacharya \& Dubey, 2011). Caregivers training has shown that there is a positive effect in viral load levels of children.

Training caregivers on the meaning and importance of viral load tests, and how ARVs work in a simple local language may be attributed to reduction in viral loads. Majority of caregivers interviewed knew what viral load meant and responded that, ARVs stop HIV replication and kept people healthy.

There were eight different opportunistic infections among HIV infected children before training and after training. After training majority of children did not experience any opportunistic infections. In contrast, children of non-trained caregivers had more opportunistic infections. ART adherence and viral load levels have been shown in this study to be factors that best predict the course of opportunistic infections. This is consistent with most studies that have also shown decrease in the risk of opportunistic infections with ART use in children in low and middle-income economies(Alarcón et al., 2012). An estimated large potential cost savings in opportunistic infections are averted with ART use even though there are greater uncertainties in pediatric data compared with that of adults(Alarcón et al., 2012). Though opportunistic infections have declined since the introduction of highly active antiretroviral therapy in developed countries, more studies were still needed to highlight the prevalence of opportunistic infections among HIV-infected children from developing countries ${ }^{6}$. This study gives strong association of caregiver training and prevalence of opportunistic infections. The study found Herpes zoster was common followed by oral candidiasis. This is corroborated by a study that looked at the prevalence of opportunistic and other infections in Latin America, which found most common infections were bacterial pneumonia, oral Candidiasis, Varicella, Tuberculosis, Herpes zoster, and Pneumocystis jiroveci pneumonia(B-Lajoie et al., 2016). Surprisingly in this study, pneumonia was found not to be the most common opportunistic infections. Though evidence from other study showed pneumonia remained a major cause of pediatric death and hospitalization in Sub-Saharan Africa(B-Lajoie et al., 2016). Currently, Kenya Expanded Program on Immunization (KEPI) includes pneumococcal vaccine at 6 weeks of birth to all under-fives children, which may prevent pneumonia in HIV infected children, this could explain the observation.

This study found caregivers training did not show significant effect on nutritional status of HIV infected 
children. There was no significant differences in nutritional status of children between trained and non-trained caregivers. Specifically, there were no differences in children with normal nutritional status though there were many children with moderate nutritional status among trained caregivers as compared to non-trained group. This is because caregivers training targeted children who were either malnourished, had poor adherence, high viral load, or those who had experienced opportunistic infections.

This study found there were no significant association between caregivers training and nutritional status of HIV infected children. This study is corroborated by the fact that, malnutrition is still a major problem in the SubSaharan Africa population. It is an additional burden for HIV-infected children because they do not respond as well as those of non-infected children to routine nutritional care(Jesson et al., 2015). Malnutrition and infections interacts with HIV-related complications in a complex way contributing to significant morbidity and mortality(Jesson et al., 2015). Food insecurity with HIV was found to be associated with childhood nutritional indicators(Mwiru et al., 2015). Interventions to improve nutritional status may be used as an adjunct to ART(Mwiru et al., 2015). Since severe malnutrition is an alarming consequence of HIV, prophylactic nutritive care and training should be considered for integration into HIV care strategies besides initiation of ART to improve nutritional status and quality of life(Jesson et al., 2015). Educating and supporting caregivers on how to make available balanced diet from available foods in the community is a sustainable venture, however caregivers training may not affect availability of food in families. Other caregivers' factors like employment, availability of external support from families may play a role.

There were varied caregivers perspectives on various dimensions of the training program. Analysis of caregiver's recollection of training program showed, most caregivers were able to remember topics on opportunistic infections, followed by nutrition and ART adherence. Caregivers interviewed gave their opinion on the benefits of HIV training, and majority reported that, training enabled them gain HIV and AIDS knowledge and adhere to treatment plan. Caregivers' opinion on what they liked about the training program varied. Most caregivers liked the fact that, they attended training. This was followed by food and other allowances that were provided during the training. Caregivers remembered HIV and AIDS topic clearly which was expected given that training program gravitated to these topics and was the main goal of the training. One caregiver commented, "At first, I did not know how to give my child medicine but caregiver training helped me a lot" Caregivers experiences on managing HIV infected children in Malawi showed that, management of HIV-infected children can be complex, especially among children who take syrups and have frequent changes of regimens(Nyando, 2014). As shown in this study before training, caregivers had difficulties in taking care of HIV infected children(Nyando, 2014).

Caregivers in Thailand also expressed their request to medical team, that they needed HIV knowledge, and skills to enable them support children on ART(Wattradul \& Sriyaporn, 2014). As corroborated in this study, one caregiver opined, "The training helped me improve my ways on how to take good care of my child". A South African study also found that there was little support available in educating caregivers on how to care of HIV infected children, especially to deal with stigma, economic, emotional and psychosocial needs from health facilities(Waudo, 2012). Caregivers reported burnouts from physical demands and psychological stress from daily activities including management of HIV infected children, especially among those who did not undergo any HIV training.

Based on the success of training, the $\mathrm{MOH}$ has already published a caregiver-training manual to be used across the country. The results of this evaluation study provide evidence that training caregivers on HIV and AIDS information improves health outcomes of HIV infected children(NASCOP, 2016). It is anticipated that this caregiver-training manual will translate to better treatment outcomes for all HIV infected children(NASCOP, 2016).

1.3.1 Study implications

Caregivers training improves health outcomes of children living with HIV. However, training may not affect nutritional status of these children. Caregivers were positive that training helped improve their knowledge and skills on ART adherence, viral load monitoring, and prevention of opportunistic infections. The availability of these results are helpful to PEPFAR implementing partners and other stakeholders in scaling up caregivers training to regions not covered by the training. Policy makers and programme implementers may use these results to inform policy dialogues, caregivers' manual revisions to scale-up training nationwide.

1.3.2 Limitations of the Study

Self-reports from caregivers may-overestimate benefits of training. This study did not look at the prevalence of opportunistic infections, but only looked at the frequencies of occurrence of opportunistic infections in children between trained and non-trained caregivers at the same period of one year after training and may not be compared or contrasted.

\subsection{Summary}

Training caregivers on HIV information improves health outcomes of HIV infected children on antiretroviral therapy. 
1.4.1 Conclusions: The study found that, training enables caregivers to improve adherence levels of HIV infected children on antiretroviral therapy. Even though there are HIV information in public domain, the study found, if this information is provided in a structured manner, enables suppression of viral loads, and significantly reduces frequency of opportunistic infections among HIV infected children on antiretroviral therapy. The study also found providing information on nutrition to caregivers does not significantly affect nutritional status of HIV infected children.

1.4.2 Recommendations: The study recommends that structured information on HIV and AIDS be given to caregivers of HIV infected children on ART adherence, viral load information, and prevention of opportunistic infections. This information should provided during clinic appointments and support groups meetings. Other interventions need to be included alongside information on nutrition to improve nutritional status of HIV infected children.

\subsection{Reference}

Alarcón, J. O., Freimanis-Hance, L., Krauss, M., Reyes, M. F., Cardoso, C. A. A., Mussi-Pinhata, M. M., ... Hazra, for the NISDI Pediatric Stud, R. (2012). Opportunistic and Other Infections in HIV-Infected Children in Latin America Compared to a Similar Cohort in the United States. AIDS Research and Human Retroviruses, 28(3), 282-288. https://doi.org/10.1089/aid.2011.0057

B-Lajoie, M.-R., Drouin, O., Bartlett, G., Nguyen, Q., Low, A., Gavriilidis, G., ... Muhe, L. (2016). Incidence and Prevalence of Opportunistic and Other Infections and the Impact of Antiretroviral Therapy Among HIVinfected Children in Low- and Middle-income Countries: A Systematic Review and Meta-analysis. Clinical Infectious Diseases, 62(12), 1586-1594. https://doi.org/10.1093/cid/ciw139

Bhattacharya, M., \& Dubey, A. P. (2011). Adherence to antiretroviral therapy and its correlates among HIVinfected children at an HIV clinic in New Delhi. Annals of Tropical Paediatrics, 31(4), 331-337. https://doi.org/10.1179/1465328111Y.0000000031

Biadgilign, S., Reda, A. A., Deribew, A., Amberbir, A., Belachew, T., Tiyou, A., \& Deribe, K. (2011). Knowledge and attitudes of caregivers of HIV-infected children toward antiretroviral treatment in Ethiopia. Patient Education and Counseling, 85(2). https://doi.org/10.1016/j.pec.2011.02.008

Dulmen, S. Van, Sluijs, E., Dijk, L. Van, Ridder, D. De, Heerdink, R., Bensing, J., \& Forum, E. (2008). Furthering patient adherence: A position paper of the international expert forum on patient adherence based on an internet forum discussion, 8, 1-8. https://doi.org/10.1186/1472-6963-8-47

Eticha, T., \& Berhane, L. (2014). Caregiver-reported adherence to antiretroviral therapy among HIV infected children in Mekelle ,. BMC Infectious Diseases, 14(1), 1-8. https://doi.org/10.1186/1471-2431-14-114

Jesson, J., Masson, D., Adonon, A., Tran, C., Habarugira, C., Zio, R., ... Nimage, A. (2015). Prevalence of malnutrition among HIV-infected children in Central and West-African HIV-care programmes supported by the Growing Up Programme in 2011: A cross-sectional study. BMC Infectious Diseases, 15(1), 1-12. https://doi.org/10.1186/s12879-015-0952-6

KDHS. (2014). Kenya. Kenya Demographic Health Survey. Nairobi, Kenya: https://doi.org/10.3109/03014460.2013.775344

Killian, M. S., \& Levy, J. A. (2011). HIV/AIDS: 30 Years of progress and future challenges. European Journal of Immunology, 41(12), 3401-3411. https://doi.org/10.1002/eji.201142082

Mwiru, R. S., Spiegelman, D., Duggan, C., Iii, G. R. S., Semu, H., Chalamilla, G., ... Fawzi, W. W. (2015). Nutritional Status and Other Baseline Predictors of Mortality among HIV-Infected Children Initiating Antiretroviral Therapy in Tanzania, 14(2), 172-179. https://doi.org/10.1177/2325957413500852

NACC. (2016). Kenya AIDS response progress report. Nairobi, Kenya:

NASCOP. (2016). The Caregivers Training Manual.Nairobi,Kenya

Nyando, M. C. (2014). The Experiences of Caregivers Looking after a Child living with HIV and AIDS in rural Malawi.Unpublished Thesis; P 47-48. Cardiff University,Malawi

Okomo, U., Togun, T., Oko, F., Peterson, K., Townend, J., Peterson, I., \& Jaye, A. (2012). Treatment outcomes among HIV-1 and HIV-2 infected children initiating antiretroviral therapy in a concentrated low prevalence setting in West Africa. BMC Pediatrics, 2012 Jul 8, 1-11.

Polisset, J., Ametonou, Æ. F., Arrive, E., Aho, Æ. A., \& Perez, Æ. F. (2009). Correlates of Adherence to Antiretroviral Therapy ', Togo , West Africa in HIV-Infected Children in Lome, $23-32$. https://doi.org/10.1007/s10461-008-9437-6

Ricci, G., Martins, E., Luz, E., Rodamilans, C., \& Brites, C. (2017). Adherence to antiretroviral therapy of Brazilian HIV-infected children and their caregivers. Brazilian Journal of Infectious Diseases, 20(5), 429436. https://doi.org/10.1016/j.bjid.2016.05.009

Sumathi Sivapalasingam, Megan Mendillo, Aabid Ahmed, Musa Mwamzuka, Swale Said, Fatma Marshed, Farhad Luhar Abdulaziz, M. F. \& R. H. (2014). The importance of caregivers in the outcome of pediatric HIV management, Mombasa, Kenya. AIDS Care;Psychological and Socio-Medical Aspects of AIDS/HIV, 26(4), 
425-433. https://doi.org/10.1080/09540121.2013.841829

UNAIDS. (2017). The Global HIV / AIDS Epidemic Update. Geneva, Switzerland.

Wattradul, D., \& Sriyaporn, A. (2014). Experiences of Caregivers in Healthcare for and Social Support of HIV Positive Children Attending Schools in Bangkok. Asian Nursing Research, 8(3), 226-231. https://doi.org/10.1016/j.anr.2014.08.001

Waudo, W. S. (2012). Factors Influencing adherence to Antiretroviral Therapy among HIV infected and HIV exposed children at Naivasha District hospital. (unpublished Thesis, University of Nairobi, P 4). Nairobi, Kenya

Xu, L., Munir, K., Kanabkaew, C., \& Le Coeur, S. (2017). Factors influencing antiretroviral treatment suboptimal adherence among perinatally hivinfected adolescents in Thailand. PLoS ONE, 12(2), 1-18. https://doi.org/10.1371/journal.pone.0172392

\section{Authors' biographies}

1. Argwings Odhiambo Miruka PhD (Student) Epidemiology \& Population Health - Maseno University School of Public Health and Community Development

2. Dr. Louisa Ndunyu; Chair and Lecturer Maseno University School of Public Health and Community Development

\section{Dr. Patrick O. Onyango}

Associate Dean School of Graduate studies; Maseno University

4. Dr. Laura Oyiengo Manager Kenya Ministry of Health, Department of Child health Nairobi, Kenya

5. Dr Maswai K. Jonah; Director, PEPFAR DOD/ HJF-SRV HIV Program US Army Medical Research Directorate, KEMRI/ Walter Reed Project, Kericho-Kenya 